\title{
Investigation of pre-coagulation and powder activate carbon adsorption on ultrafiltration membrane fouling
}

\author{
Wenzheng $\mathrm{Yu}^{\mathrm{a}, 1}$, Lei $\mathrm{Xu}^{\mathrm{a}, 1}$, Jiuhui $\mathrm{Qu}{ }^{\mathrm{a}, *}$, Nigel Graham ${ }^{\mathrm{b}}$ \\ a State Key Laboratory of Environmental Aquatic Chemistry, Research Center for Eco-Environmental Sciences, Chinese Academy of Sciences, \\ Beijing 100085, China \\ ${ }^{\mathrm{b}}$ Department of Civil and Environmental Engineering, Imperial College London, South Kensington Campus, London SW7 2AZ, UK
}

\section{A R T I C L E I N F O}

\section{Article history:}

Received 18 November 2013

Received in revised form

3 February 2014

Accepted 4 February 2014

Available online 11 February 2014

Keywords:

Coagulation

Ultrafiltration

PAC

Crystallization

Fouling

\begin{abstract}
A B S T R A C T
Pre-coagulation by alum before ultrafiltration without (CUF) and with (CAUF) powdered activated carbon (PAC) addition was investigated to explore the influence of PAC on membrane fouling. It was found that the continuous addition of a low dosage of PAC reduced membrane fouling for operational run periods $<20$ days, both for reversible and for irreversible components of fouling. The presence of PAC increased the removal of dissolved organic matter (DOM), particularly proteinaceous substances, and some fractions of humic-type substances. For a longer operation time ( $>20$ days) an increase in mainly reversible fouling was evident and was attributed to microorganism growth in the cake layer, as indicated by the enhanced concentrations of extracellular polymeric substances, such as polysaccharides and proteins. A process of crystallization of the coagulant floc in the cake layer with increasing operation time was believed to cause desorption of DOM from primary coagulation particles and a decrease in their size, and consequently a higher density of cake layer. PAC absorption of desorbed DOM within the cake layer, and residual DOM after coagulation, reduced DOM reaching the membrane surface and the extent of subsequent internal membrane fouling.
\end{abstract}

Crown Copyright (c) 2014 Published by Elsevier B.V. All rights reserved.

\section{Introduction}

Ultrafiltration (UF) membrane systems are an attractive alternative for the treatment of ground waters and surface waters for potable water supply since they can economically achieve a consistently high quality of drinking water. However, natural organic matter (NOM) is often a major foulant during the ultrafiltration of surface water $[1,2]$, since it contains a complex mixture of humic and fulvic acids, proteins, carbohydrates of various molecular sizes and functional groups [2-5], which can either bind to the membrane surface or support the development of microbiological fouling.

Pretreatment before UF, especially by "in-line" chemical coagulation or coagulation-hydraulic flocculation, has been shown to be an effective way to control membrane fouling [6-8], and improve general water quality $[1,9,10]$. However, not all contaminants can be fully removed by the coagulation process, particularly biopolymers, such as polysaccharides and proteins [3-5]. In view of this, the combination of powder activate carbon

\footnotetext{
* Corresponding author. Tel.: +8610 62849128; fax: +86 1062849160 .

E-mail addresses: wzyu@rcees.ac.cn (W. Yu), jhqu@rcees.ac.cn (J. Qu), n.graham@imperial.ac.uk (N. Graham).

${ }^{1}$ Did the same work quantity as co-first authors.
}

(PAC) adsorption and UF has been reported to be more effective in the removal of organic contaminants, either as represented by total organic carbon or any other special pollutants [11-16]. However, the addition of PAC may influence membrane fouling.

Currently there is no clear consensus concerning the effect of PAC addition on the flux of membrane filtration. Some researchers have reported that PAC was ineffective at reducing membrane fouling despite it enhancing the removal of micromolecular NOM [13,17-19], and regardless of the NOM characteristics (hydrophobicity and protein content) and inorganic content of the water [20]. Alternatively, some researchers have found that PAC can improve membrane flux $[13,21-23]$. The reason for the improved membrane performance was because the PAC acts as a scouring agent which limits foulant deposition or controls irreversible membrane fouling, and the effect of the combined adsorption and biodegradation by the biologically active PAC on the foulant components [20,24].

In contrast, other studies have indicated that the addition of PAC caused higher membrane fouling [25-27]; the reasons for this have been stated to be because PAC adsorbed non-fouling molecules preferentially over foulants, although PAC removed a larger fraction of the organic matter [28], and that the attachment of NOM to PAC particles led to an increase in cake layer resistance [29]. Overdosing of PAC contributes to fouling by blocking the membrane pores [30] 
or by forming a cake layer which increases the reversible resistance [31]. Therefore, it can be concluded that PAC, as a sole pretreatment, can improve organic matter removal, but it may have an adverse impact on membrane fouling.

Previous studies involving coagulation have compared combined coagulation/microfiltration (MF) and PAC/MF, and found that there was a similar performance for organic matter removal, but coagulation/MF resulted in a significant decrease in flux [32]. Alternatively, some authors have recognized the potential benefits of a combined coagulation and PAC adsorption process before membrane filtration [33]; however, in these cases the membrane operation process lasted for only $30 \mathrm{~min}$ [12], or less than $5 \mathrm{~h}$ [17]. Matsui et al. [34] found that both physically reversible and irreversible membrane fouling were reduced by a combination of PAC and polyaluminum chloride (PACl) pretreatment, because of a high NOM removal and the formation of larger and more porous flocs. Dialynas and Diamadopoulos [35] found that after the addition of PAC to a coagulation-UF system, the trans-membrane pressure increased rapidly due to the formation of the PAC cake on the membrane surface, but there was a high degree of organic matter removal.

In light of the previous studies summarized above, there is no consensus as to whether the addition of PAC can mitigate or aggravate membrane fouling. In this paper, the impact of adding a low dosage of PAC with alum as the pretreatment before UF membrane filtration has been examined in terms of the nature and extent of membrane fouling. This paper provides additional information, including that relating to bacteria and extracellular polymeric substances (EPS), and the adsorption of organic matter released from the cake layer by PAC in short and long ages, to the limited work reported so far concerning the combined use of PAC and alum coagulant before UF membrane filtration.

\section{Materials and methods}

\subsection{Synthetic raw water and coagulant}

Synthetic raw water was chosen for the tests in order to simplify the study to provide sample consistency and reproducibility. Domestic sewage was added to the local (Beijing, China) tap water with a volumetric ratio of 1:50 to simulate a surface water supply slightly polluted by sewage discharges. In addition, $5 \mathrm{mg} / \mathrm{L}$ of humic acid (HA, sodium salt, Aldrich, Cat: H1, 675-2) was added to the raw water. Prior to mixing with domestic sewage and humic acid solution, the tap water was left overnight to ensure the complete decay of residual chlorine, which may inactivate/kill the bacteria. The characteristics of the synthetic raw water are listed in Table 1. During the course of the experimental program the temperature of the water was $20 \pm 2{ }^{\circ} \mathrm{C}$.
Aluminum sulfate hydrate $\left(\mathrm{Al}_{2}\left(\mathrm{SO}_{4}\right)_{3} \cdot 18 \mathrm{H}_{2} \mathrm{O}\right.$; Bodi, China, $>99 \%$ ), 'alum', was used as a coagulant in this study. Stock alum solution was prepared at a concentration of $0.1 \mathrm{M}$ in de-ionized (DI) water. A stock powdered activated carbon suspension (PAC, $<20 \mu \mathrm{m}$, Shanghai) was prepared at a concentration of $5 \mathrm{~g} / \mathrm{L}$.

\subsection{Pretreatment before UF processes}

Conventional coagulation and flocculation by alum without and with PAC addition (at a concentration of $10 \mathrm{mg} / \mathrm{L}$ ) before ultrafiltration (CUF/CAUF, respectively) were operated in parallel. A schematic illustration of the CUF and CAUF arrangements is shown in Fig. 1. Synthetic raw water was supplied to a constantlevel tank to maintain the water head for the membrane tanks. An optimal alum dose of $0.15 \mathrm{mM}$ (determined by pre-experiments) was continuously added to the rapid mixing tanks, which had a stirring speed of $200 \mathrm{rpm}\left(G=184 \mathrm{~s}^{-1}\right.$; determined in our previous work [36]) and a hydraulic retention time (HRT) of $1 \mathrm{~min}$. After mixing, the flow passed to three flocculation tanks, with each having a stirring speed of $50 \mathrm{rpm}\left(G=23 \mathrm{~s}^{-1}\right)$ and an HRT of $5 \mathrm{~min}$. For tests with PAC, $10 \mathrm{mg} / \mathrm{L}$ PAC was added to the first flocculation tank to ensure sufficient contact time for adsorption prior to UF separation. After the flocculation tanks, the flow passed directly to the membrane tanks. Each tank contained a submerged polyvinylidenefluoride (PVDF) hollow-fiber UF membrane module (Tianjin Motimo Membrane Technology Co., Ltd., China) where the membrane had a nominal pore size of $0.03 \mu \mathrm{m}$ and a surface area of $0.025 \mathrm{~m}^{2}$. The permeate from the submerged membrane module was continuously withdrawn by a peristaltic pump at a constant flux of $20 \mathrm{~L} \mathrm{~m}^{-2} \mathrm{~h}^{-1}$, operated in a cycle of $30 \mathrm{~min}$ filtration and $1 \mathrm{~min}$ backwash $\left(40 \mathrm{~L} \mathrm{~m}^{-2} \mathrm{~h}^{-1}\right)$. For each backwash, air was supplied to each reactor at $100 \mathrm{~L} / \mathrm{h}$ (air:water $=200: 1$ ). The transmembrane pressure (TMP) was continuously monitored by pressure gauges. The HRT of the membrane tanks was maintained at $0.5 \mathrm{~h}$ and accumulated sludge was released every 3 days. The cake layer on the surface of the membrane was washed away by a highpressure tap water and sponge application twice during the whole operation process (63 days). It is noted that direct ultrafiltration without pretreatment caused significantly higher membrane fouling than with pretreatment, and this was not compared here [37].

\subsection{Samples of cake layer and sludge}

At the end of operation, the fouled membrane modules were taken out from the membrane tanks. The cake layer on the membrane surface was carefully scraped off with a plastic sheet (Deli, China), and analyzed by the following methods to characterize the external membrane fouling. The extraction of internal fouling is described later.

Table 1

Water quality of raw water and UF influents ${ }^{\mathrm{a}} /$ filtrates. $^{\mathrm{b}}$

\begin{tabular}{|c|c|c|c|c|c|}
\hline Parameter $^{\mathrm{c}}$ & Raw water & CUF influent & CAUF influent & CUF filtrate & CAUF filtrate \\
\hline $\mathrm{UV}_{254}\left(\mathrm{~cm}^{-1}\right)$ & $0.115 \pm 0.006$ & $0.029 \pm 0.002$ & $0.023 \pm 0.002$ & $0.027 \pm 0.003$ & $0.020 \pm 0.002$ \\
\hline $\mathrm{DOC}(\mathrm{mg} / \mathrm{L})$ & $4.956 \pm 0.415$ & $2.843 \pm 0.185$ & $2.532 \pm 0.302$ & $2.572 \pm 0.234$ & $2.188 \pm 0.287$ \\
\hline Turbidity (NTU) & $3.69 \pm 0.16$ & $2.03 \pm 0.18$ & $1.75 \pm 0.21$ & $0.05 \pm 0.02$ & $0.06 \pm 0.03$ \\
\hline $\mathrm{Al}(\mathrm{mg} / \mathrm{L})$ & $0.050 \pm 0.002$ & $0.079 \pm 0.001$ & $0.069 \pm 0.003$ & $0.067 \pm 0.001$ & $0.065 \pm 0.003$ \\
\hline $\mathrm{P}(\mathrm{mg} / \mathrm{L})$ & $0.259 \pm 0.061$ & $0.062 \pm 0.014$ & $0.073 \pm 0.010$ & $0.061 \pm 0.013$ & $0.060 \pm 0.010$ \\
\hline $\mathrm{NH}_{4}^{+}-\mathrm{N}(\mathrm{mg} / \mathrm{L})^{\mathrm{d}}$ & $0.934 \pm 0.145$ & $0.252 \pm 0.069$ & $0.482 \pm 0.104$ & $0.125 \pm 0.035$ & $0.305 \pm 0.045$ \\
\hline $\mathrm{pH}$ & $7.93 \pm 0.06$ & $7.02 \pm 0.04$ & $7.01 \pm 0.04$ & $7.04 \pm 0.05$ & $7.03 \pm 0.03$ \\
\hline
\end{tabular}

a Influent - within membrane tank, immediately after flocculation units.

b The values in Table 1 are averages for all the measurements during the 3 stages.

${ }^{c}$ Number of measurements $(n)$ : For turbidity, $\mathrm{UV}_{254}$, and DOC, $n=9$; for residual Al, and P, $n=5$.

${ }^{\mathrm{d}} \mathrm{NH}_{4}^{+}-\mathrm{N}(\mathrm{mg} / \mathrm{L})$ in CAUF was measured in the early period (less than 20 days) of the three stages, and it was nearly the same as that in the CUF at the end of the first stage. 


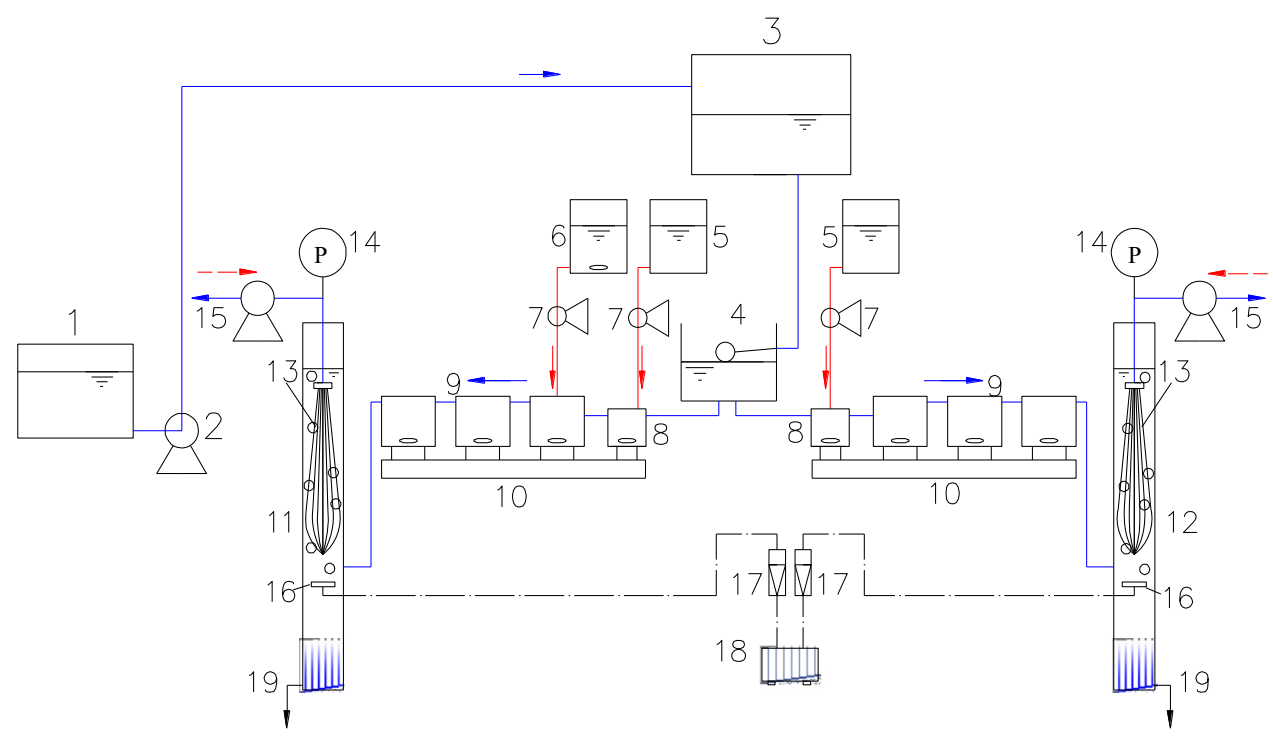

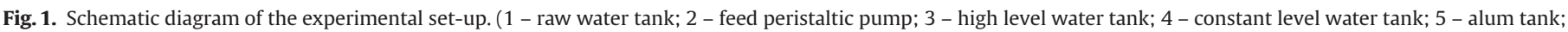

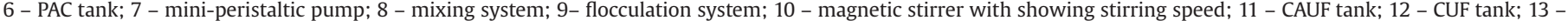
UF membrane module; 14 - pressure gauge; 15 - suction/backwash peristaltic pump; 16 - air blower; 17 - air flowmeter; 18 - air diffuser; 19 - sludge discharge)

\subsubsection{XRD and BET measurement}

Subsamples of cake layer and new sludge (just after settlement in the membrane tank) after freeze drying were mounted in 1mm-thick glass sample holders for X-ray diffraction (XRD, X-Pert PRO MPD, Philips, Netherlands) analysis, and diffraction patterns were recorded by unresolved $\mathrm{Cu}-\mathrm{K} \alpha$ radiation at $40 \mathrm{kV}$ and $40 \mathrm{~mA}$.

The BET surface area of new PAC, and the cake layer and sludge after freeze-drying in the CUF and CAUF, was measured by ASAP 2020 (Micromeritics, USA).

\subsubsection{Extraction of extracellular polymeric substances (EPS)}

Some of the collected liquid samples after centrifugation (as suspended solid, SS) were fully mixed in phosphate buffer saline (PBS) solution, and the mixed liquor was then heated to $80{ }^{\circ} \mathrm{C}$ for $1 \mathrm{~h}$. The heated liquor was cooled at room temperature and centrifuged at $10,000 \mathrm{~g}$ for $40 \mathrm{~min}$, and the supernatant was filtered through a $0.45 \mu \mathrm{m}$ membrane and taken to represent the bound EPS fraction for chemical analyses, as described by Wang et al. [38] and Yu et al. [39]. The EPS were extracted in duplicate for each sample.

After the membrane surface was wiped with a sponge, $0.01 \mathrm{~mol} / \mathrm{L} \mathrm{NaOH}$ was used for extraction of internal foulants and the fibers were soaked for $24 \mathrm{~h}$ at $20^{\circ} \mathrm{C}$ in the alkaline solution according to the method described by Kimura et al. [40]. The extracted organic matter was then subjected to the following chemical analyses.

\subsubsection{Total EPS concentration and DNA analysis}

The polysaccharide content in the bound EPS was measured by the phenol-sulfuric acid method with glucose as the standard [41]. A modification of the Bradford method [42], called the Coomassie procedure (Pierce Chemical), was used to quantify proteins, with bovine serum albumin (Sigma) as the standard.

The DNA in the cake layer and sludge were extracted following the procedures given by the extraction kit (Fast DNA ${ }^{@}$ Spin kit for soil, Lot 19744, MP, USA), which was described by Zhang and Fang [43], previously. The DNA contents were measured by UV adsorption at $260 \mathrm{~nm}$ (NanoDrop 2000 spectrophotometer, Thermo Scientific, USA).

\subsubsection{Three-dimensional excitation-emission matrix (EEM) fluorescence spectroscopy}

Fluorescence measurements were conducted using a spectrofluorometer (FP-6500, Jasco, Japan) equipped with a 150 Wxenon lamp at an ambient temperature of $25^{\circ} \mathrm{C}$. A 1 -cm quartz cuvette with four optical windows was used for the analyses.

Emission scans were performed from 250 to $600 \mathrm{~nm}$ at $5 \mathrm{~nm}$ steps, with excitation wavelengths from 200 to $500 \mathrm{~nm}$ at $5 \mathrm{~nm}$ intervals. The detector was set to high sensitivity, and the scanning speed was maintained at $2400 \mathrm{~nm} / \mathrm{min}$ in this study; the slit widths for excitation and emission were $5 \mathrm{~nm}$ and $5 \mathrm{~nm}$, respectively. Under the same conditions, fluorescence spectra for Milli-Q water were subtracted from all the spectra to eliminate Raman scattering of water and to reduce other background noise. The EEM spectra are plotted as the elliptical shape of contours.

\subsubsection{Size exclusion chromatography}

Size exclusion chromatography (SEC) was carried out to determine the apparent molecular weight (MW) distribution of UV-active substances in the waters from the CUF and CAUF systems, as well as the organic matter (EPS) extracted from the cake layers and sludges. SEC was performed using a TSK G3000SW $\mathrm{xl}_{\mathrm{xl}}$ (TOSOH Biosep, $5 \mu \mathrm{m}$ resin) column $(7.8 \mathrm{~mm} \times 300 \mathrm{~mm})$ with $20 \mathrm{mM}$ phosphate buffer $\left(1.36 \mathrm{~g} / \mathrm{L} \mathrm{KH_{2 }} \mathrm{PO}_{4}\right.$ and $\left.3.58 \mathrm{~g} / \mathrm{L} \mathrm{Na} \mathrm{Na}_{2} \mathrm{HPO}_{4}\right)$ at a $\mathrm{pH}$ of 6.85 as the mobile phase. The measurement was carried out by an integrated GPC system (PL-GPC 50, Agilent, USA) with UV detection (G1314B, VWDVL, 1200, Agilent) at $254 \mathrm{~nm}$. The flow rate was set at $0.6 \mathrm{~mL} / \mathrm{min}$, and the injection volume of water samples was $100 \mu \mathrm{L}$. Polystyrene sulfonate (PSS) standards (American Polymer Standard Corp., US) of molecular weights 15,650, 6200, 4600, and $1360 \mathrm{Da}$ were employed to calibrate the relationship between the MW and the retention time. This procedure was adapted from the method described by Allpike et al. [44].

\subsubsection{SEM measurement}

Fouled membrane fibers were cut from the two membrane modules, and the foulant layer attached on the membrane surface was retained on the membrane surface. The new and fouled membrane samples after being air-dried were then platinumcoated by a sputter and observed under scanning electron microscopy (SEM; JSM7401F, JEDL, Japan). 


\subsection{Other analytical methods}

The UV absorbance at $254 \mathrm{~nm}, U_{254}$, of $0.45 \mu \mathrm{m}$ filtered solutions was determined by an ultraviolet/visible spectrophotometer (U-3010, Hitachi High Technologies Co., Japan). Dissolved organic carbon (DOC, after $0.45 \mu \mathrm{m}$ cellulose nitrate membrane filter) was determined with a total organic carbon (TOC) analyzer (TOC-V $\mathrm{V}_{\mathrm{CPH}}$, Shimadzu, Japan). Residual aluminum and total phosphorus $(\mathrm{P})$ concentration after $0.45 \mu \mathrm{m}$ membrane filtration were measured by inductivity coupled plasma optical emission spectrometer (ICP-OES, 710, Agilent Technologies, USA). Residual turbidity measurements (Hach2100, USA) were made for samples in the two membrane tanks. The concentration of $\mathrm{NH}_{4}^{+}-\mathrm{N}$ was determined by the colorimetric method using a spectrometer by APHA Standard Methods [45].

\section{Results}

\subsection{TMP developments in CUF and CAUF systems}

The addition of PAC after alum before ultrafiltration (CAUF) was compared with that using only alum (CUF). In these experiments, the membrane flux of the CUF and CAUF streams were both set at a constant value of $20 \mathrm{~L} \mathrm{~m}^{-2} \mathrm{~h}^{-1}$ in a cycle of $30 \mathrm{~min}$ filtration/ 1 min water backwash, and membrane fouling was represented by the increase in TMP. An example of the comparative increase in TMP for the CUF and CAUF streams is shown in Fig. 2, which covered three stages of operation over 63 days. It can be seen that the TMP increased with time from an initial value of approximately $5 \mathrm{kPa}$ in all cases.

Comparing the two types of pretreatment, it was evident that membrane fouling was significantly different if the membrane filtration was continued for different run times. The combination of alum and PAC produced a membrane fouling rate much lower than that of only alum in the early days of the first stage of 28 days' operation (Fig. 2); however, the TMP increased rapidly after 20 days of operation, and it was greater on the 27th day than in the CUF. It is suggested that biological developments on the retained PAC in the CAUF might be the main reason for this higher membrane fouling after the long operation time ( $>20$ days).

After 28 days of operation, the membrane modules were taken out from the tanks and cleaned by high-pressure tap water and sponge. It can be seen that the TMP of the CUF and CAUF membranes after washing was $7 \mathrm{kPa}$ and $6 \mathrm{kPa}$, respectively, and these were only a little higher than those of a new membrane. Therefore, we can conclude that membrane fouling was mainly

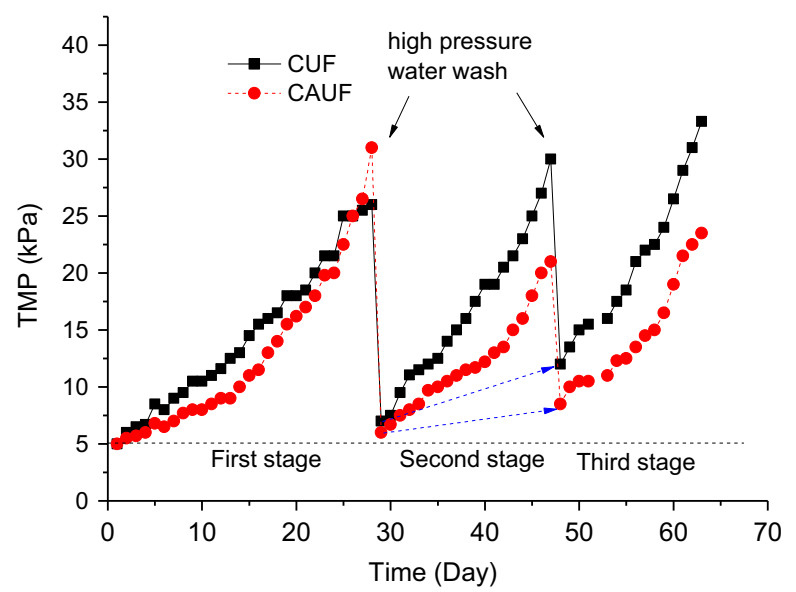

Fig. 2. Variation of TMP with time and different pretreatment conditions over a period of approximately 65 days $\left(20 \mathrm{~L} \mathrm{~m}^{-2} \mathrm{~h}^{-1}\right)$. determined by the cake layer on the surface of the membrane if the operation time did not last longer than 28 days. It can also be seen that there was only some minor irreversible membrane fouling after 28 days' operation.

The rate of increase of TMP in the CAUF was again much lower than that in CUF in the second stage with 20 days' operation, and the final TMP was $30 \mathrm{kPa}$ and $22 \mathrm{kPa}$ for CUF and CAUF membranes, respectively. The results suggest that membrane fouling can be controlled by the presence of PAC over 20 days' operation. After the second membrane cleaning using high-pressure water wash and sponge, the TMP decreased to $13 \mathrm{kPa}$ and $8.5 \mathrm{kPa}$ for CUF and CAUF, respectively. The subsequent rate of increase of TMP in the third stage was again greater for CUF than that for CAUF for $<20$ days' operation. Therefore, the series of three stages of operation showed that the presence of PAC can mitigate irreversible and reversible membrane fouling if the operation process was controlled to prevent biological effects (by avoiding long membrane run times). In view of this, further investigation of UF performance with PAC addition as part of the pretreatment was undertaken.

\subsection{Variation of dissolved organic matter (DOM) in the water}

Although most of the organic matter in the synthetic raw water can be removed (by incorporation/adsorption) in the pretreatment process, the residual DOM may still induce membrane fouling after a long operation time of membrane filtration. The addition of PAC was found to remove more organic matter, as indicated by DOC and $\mathrm{UV}_{254}$ values given in Table 1. Here, SEC and EEM were used to distinguish molecular weight (MW) fractions of DOM and certain classes of organic matter, respectively $[40,44]$.

The apparent MW distributions of DOM in the influent, mixed liquor and effluent from CUF and CAUF systems were measured using SEC and given in terms of UV absorbance at $254 \mathrm{~nm}$. As shown in Fig. 3a, the absorbance peaks $\left(10^{4}>\mathrm{MW}>10^{2}\right)$ for the CAUF influent waters and effluent waters were lower than those for the CUF, and much lower than the peak for the raw water, especially for MW distribution between 4000 and 1000 . The differences were most likely due to adsorption of organic matter by PAC in the CAUF system. Although high MW organic matter $\left(10^{6}>\mathrm{MW}>10^{4}\right)$ was greatly removed by both CAUF and CUF systems, it was not easy to distinguish the EPS $\left(10^{6}-10^{4}\right)$ removal efficiency by the two pretreatment processes, as the response of SEC with $U_{254}$ detection is very low for protein-like substances.

EEM can distinguish different components of organic matter by characteristic fluorescence peaks. According to the research of Baker [46], there are five key fluorescence peaks referred to as fluorophores A, C, T,$T_{2}$ and $\mathrm{B}$, commonly observed in freshwater samples, as shown in Fig. 3. Peaks $A$ and $C$ are related to humiclike substances derived from the breakdown of plant material, whereas protein-like fluorophores including tryptophan-like (peak T) and tyrosine-like (peak B) materials are usually detected at enhanced levels in water impacted by domestic sewage [47], which corresponds well to the synthetic raw water used in this study. As shown in Fig. 3, peaks B and C had relatively low fluorescence intensities for the DOM samples here, so the other three peaks, $A, T_{1}$ and $T_{2}$, which are distinctly visible, are discussed in this section. The fluorescence parameters include peak location and fluorescence intensity, which reflect the differences in composition and concentration.

Generally, the reduction in intensity of the fluorescence peak between raw water and treated water is an indication of the removal of these components of organic matter. It can be seen from Fig. 3 that the coagulation process decreased the fluorescence intensities of the CUF influent of peak A by $35 \%$ and those of peaks 

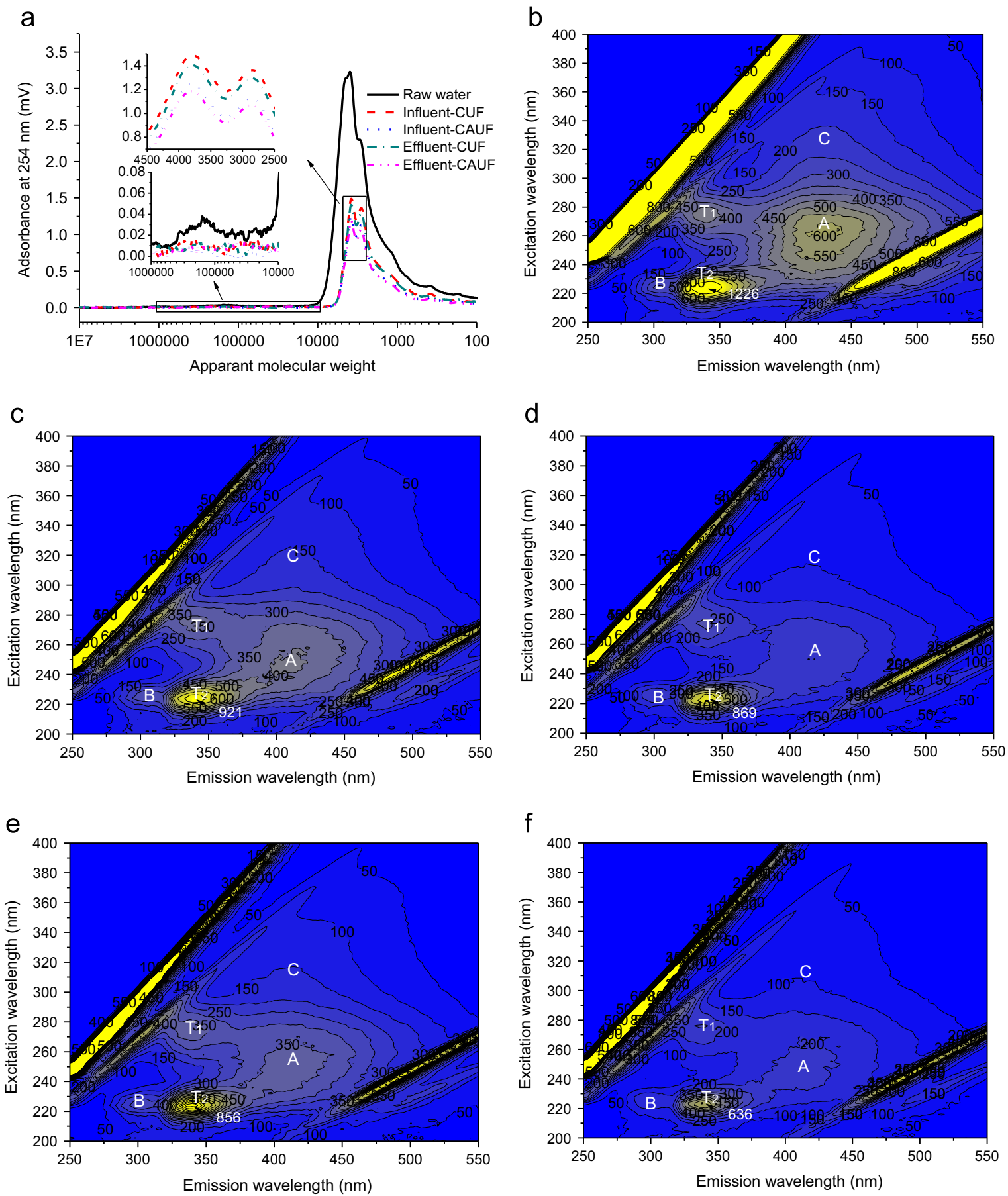

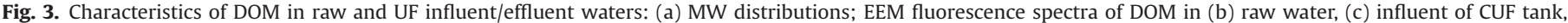
(d) influent of CAUF tank, (e) effluent of CUF, and (f) effluent of CAUF.

$\mathrm{T}_{1}$ and $\mathrm{T}_{2}$ by $30 \%$ and $25 \%$, respectively, in approximate terms, compared to the DOM in the synthetic raw water. In comparison, the fluorescence intensities of peaks $A, T_{1}$ and $T_{2}$ in the EEM spectra of CAUF influent decrease by $42 \%, 44 \%$ and $30 \%$, respectively. The intensities of peaks $A, T_{1}$ and $T_{2}$ in the EEM spectra of the UF effluents of both systems decreased compared to their respective UF influents, especially for peaks $T_{1}$ and $T_{2}$. The greater removal of protein-like substances corresponding to peaks $\mathrm{T}_{1}$ and $\mathrm{T}_{2}$ meant that PAC in the CAUF layer can remove more of these substances, and they can increase the concentration of microorganisms in the CAUF cake layer. The reduction in the fluorescence intensities of the influent and effluent in each system indicates that some organic matter was retained on the cake layer and/or within the membrane pores.

The changes in the location of the fluorescence peaks in the EEM spectra provide information about the relative presence of the chemical components of the raw water and the coagulated waters. Comparing the location of peak A for the CUF and CAUF influents and raw water, it was evident that the species of organic matter removed by coagulation and PAC adsorption was markedly different. After coagulation, the locations of the A fluorescence peaks shifted toward shorter wavelengths (blue shift) on the emission scale ( $430-420 \mathrm{~nm})$, whereas the adsorption by PAC did not change the location of peak A. There was also no peak 
a

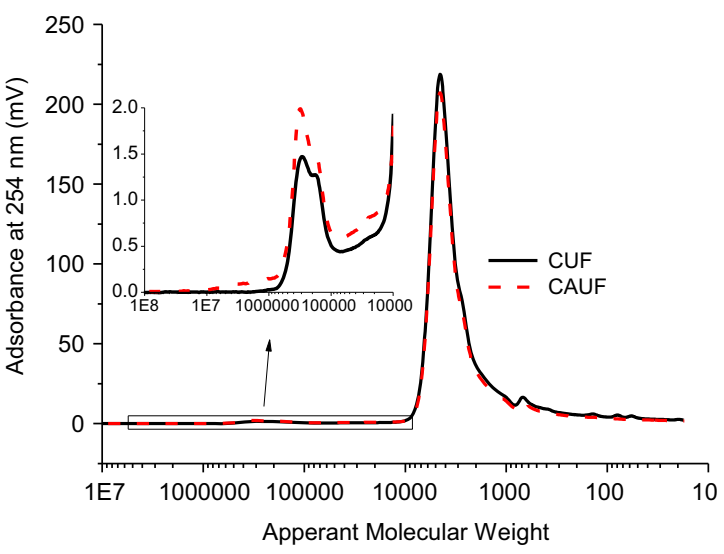

b

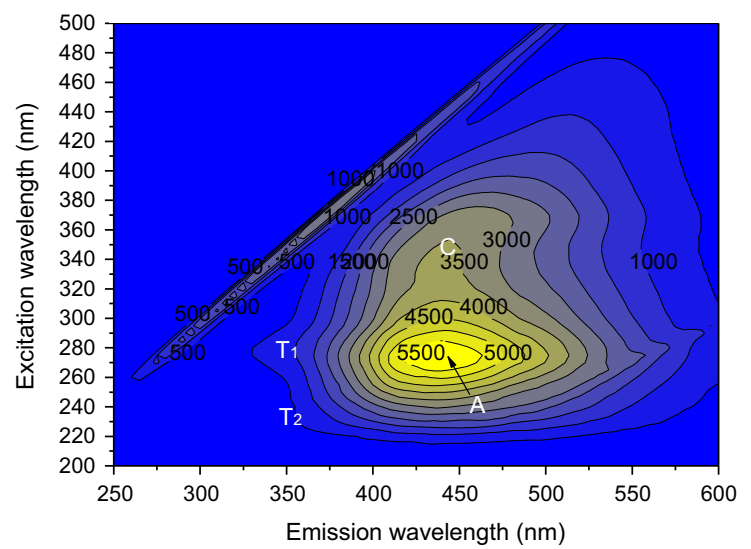

d

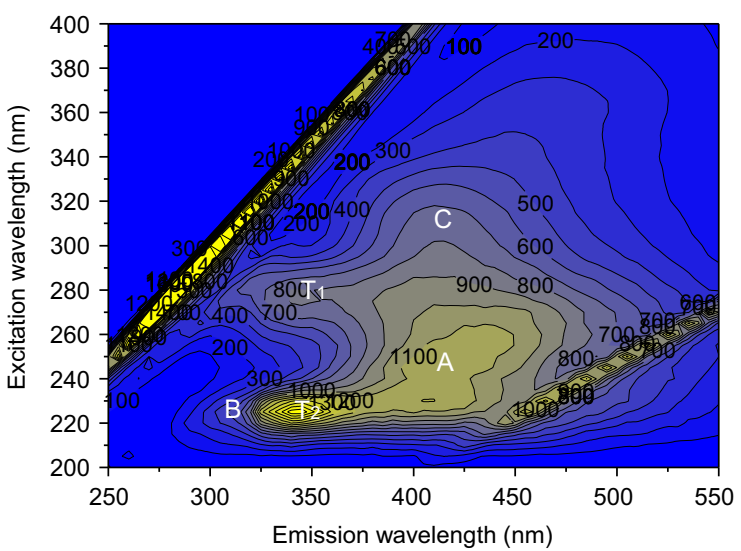

C

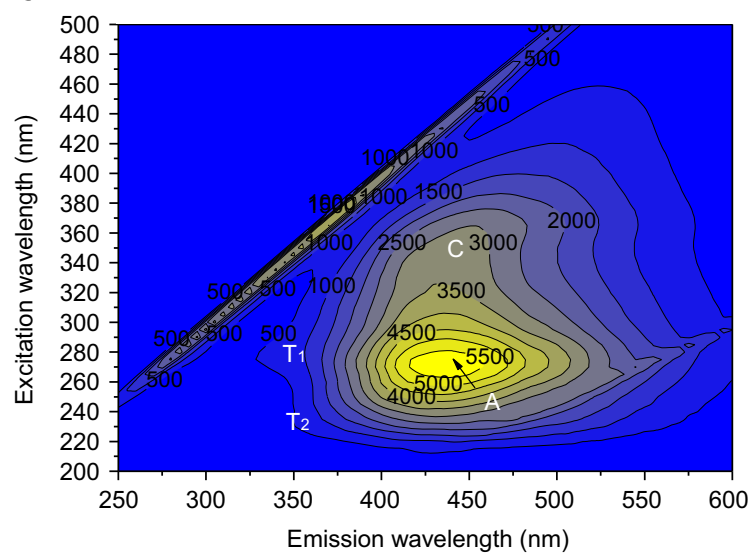

e

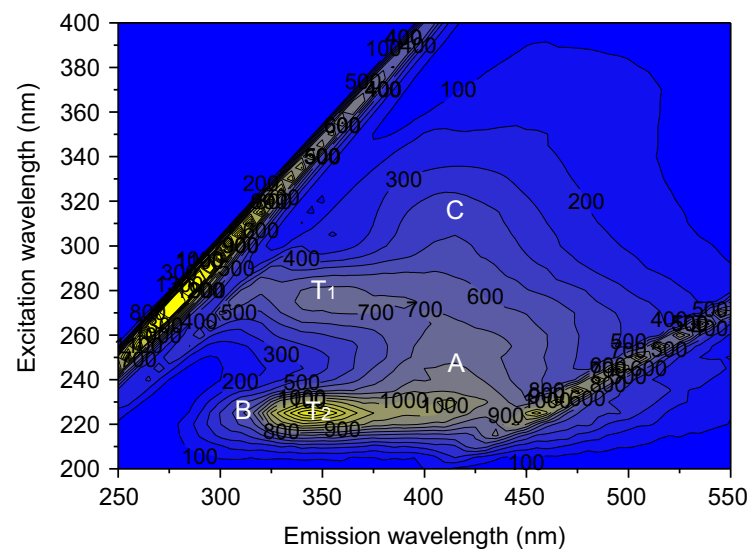

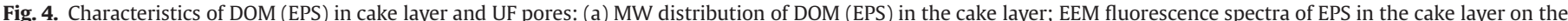
surface of CUF (b) and CAUF (c) membranes, and in the CUF (d) and CAUF (e) membrane pores.

shift for the influent and effluent of membrane tanks in the two systems, which meant that the components were relatively consistent. A blue shift is ascribed to the elimination of particular functional groups such as carbonyl, hydroxyl and amine, a reduction in the degree of p-electron systems [48], and the decrease in the number of aromatic rings and conjugated bonds in chain structures [49]. This difference between the two UF systems was a consequence of the removal of different fractions of the humic-like substances in the raw water during the coagulation and adsorption processes. It is also likely that some of the EEM peak shifts result from the changes in concentration of one of the several overlapping components [50].

\subsection{Comparison of EPS on the membrane}

In most cases, as reported in many studies previously, deposits of the foulant material have been found both on the external membrane surface and to some extent inside membrane pores [51]. Hence, in our tests both external foulants (cake layer) and internal foulants (in membrane pores) were extracted from the fouled membranes and analyzed using SEC and EEM spectroscopy at the end of their operation (Fig. 4).

The EPS extracted from the cake layer at the end of the first stage on the surface of two membranes was expressed as MW distributions (Fig. 4a) and EEM spectra (Fig. 4b and c). It was found 
that the dominant organic matter was HA substances with MW between $10^{3}$ and $10^{4}$. The concentration of organic matter with MW between $10^{4}$ and $10^{7}$ was greater in the CAUF cake layer than in the CUF cake layer, whereas it was nearly the same for the dominant MW between $10^{3}$ and $10^{4}$. The presence of PAC assists in accumulating organic matter, especially the protein-like and polysaccharide substances from microorganisms and raw water, which may be the main reason for the higher external fouling observed in the CAUF system in the later part of the first operation stage.

The EEM fluorescence spectra of external foulants in the CUF and CAUF systems are shown in Fig. $4 \mathrm{~b}$ and c. It was evident that the external foulants were composed of humic-like substances as the most prominent components in the cake layer of the two systems, as represented by peak $A$. The results indicated the accumulation of humic acid-like substances on the membrane surface in both membranes, and the intensity of peak A in CUF, was similar with that in CAUF, which was confirmed by the SEC results in Fig. 4a. Although peak $\mathrm{T}_{1}$ and peak $\mathrm{T}_{2}$ were overlapped by peak $A$, both the peaks can be differentiated, which showed that there were some protein-like materials in the cake layer.

The characteristics of the EEM fluorescence spectra of internal foulants were significantly different from those of the external foulants. It was noticed that less organic matter had deposited or adsorbed in the membrane pores, which caused a lower degree of internal fouling (Fig. 4d and e), suggesting that coagulation and PAC adsorption performed well as a pretreatment process. All of the peak fluorescence intensities of internal foulants from the CAUF were much weaker than those from the CUF, which was consistent with the observed internal fouling resistances indicated by the TMP variation in the period following cleaning by highpressure water wash and sponging (Fig. 2). Comparing the EEM fluorescence spectra of the internal foulants from the two membrane systems, it was evident that all of the five main peaks were similarly located with a difference of no more than $5 \mathrm{~nm}$ along the two axes. Also the spectra were very similar to those of the UF influent and effluent (Fig. 3c-f), which indicated that the residual NOM after coagulation or adsorption was the main cause of internal fouling. Among these peaks, peak $\mathrm{T}_{2}$ at $\mathrm{Ex} / \mathrm{Em}=325$ / $225 \mathrm{~nm}$ predominated in both EEM fluorescence spectra, indicating that the protein-like substances were the dominant components of the internal foulants. This is consistent with the findings of Hong et al. [52] and Drews et al. [53], who reported that proteins could induce severe membrane fouling owing to their presence as one of the major components in the membrane foulant material.

\subsection{Characteristics of cake layer and its EPS and DNA concentration}

As investigated in pre-experiments, the addition of PAC did not greatly change the coagulation efficiency (floc size) and the size distribution of particles in membrane tanks (Fig. 1S). This indicated that PAC was covered by the nano-scale primary particles and the attachment ability of flocs onto the cake layer was not changed. Therefore, possible changes to the structural properties of the cake layer by the presence of PAC may not be involved in the factors causing membrane fouling.

Other properties of the cake layer and sludge, which was also sampled at the end of the first stage, were explored here. It was found that the moisture content of the cake layer was much lower than that of the sludge (Table 2), which suggested that nano-scale particles had been compressed after the long UF operation time. The moisture content of the CUF cake layer was nearly the same as that of CAUF.

The BET areas of sludges in CUF and CAUF were $151.3 \mathrm{~m}^{2} / \mathrm{g}$ and $484.8 \mathrm{~m}^{2} / \mathrm{g}$, respectively, whereas those for the cake layers were $108.5 \mathrm{~m}^{2} / \mathrm{g}$ and $295.4 \mathrm{~m}^{2} / \mathrm{g}$. These values show that a low dosage
Table 2

The moisture content and BET values of cake layers and sludges (at the end of phase 1 of UF operation).

\begin{tabular}{|c|c|c|c|c|c|}
\hline \multirow[t]{2}{*}{ Parameter } & \multirow[t]{2}{*}{ PAC } & \multicolumn{2}{|c|}{ Cake layer } & \multicolumn{2}{|l|}{ Sludge } \\
\hline & & CUF & CAUF & CUF & CAUF \\
\hline Moisture content & 1 & $90.2 \%$ & $89.5 \%$ & $94.6 \%$ & $93.1 \%$ \\
\hline $\mathrm{BET} \mathrm{m}^{2} / \mathrm{g}$ & 1390.9 & 108.5 & 295.4 & 151.3 & 484.8 \\
\hline
\end{tabular}

of PAC can greatly improve the adsorption area of flocs or the cake layer and that DOM was absorbed by the cake layers after a long operation time of membrane filtration, causing the decrease in the BET area.

The larger BET area of the CAUF cake layer showed that more DOM can be adsorbed than in the CUF cake layer, including biodegradable DOM, thereby leading to a higher microorganism concentration, which produced a greater EPS concentration. Bound EPS are composed of various organic substances [54,55], and the main substances were polysaccharide and protein. Here the EPS and DNA concentrations (from microorganisms) in the cake layer and sludge (Fig. 5) were investigated, to explore their effect on membrane fouling.

Comparing the EPS content in the sludge and cake layer of the two systems, a high EPS concentration was found in the cake layer for both systems in our study (Fig. 5). Lin et al. [56] and Yu et al. [39] obtained the same results in their experiments concerned with wastewater treatment. The amount of bound polysaccharide $(135.0 \mu \mathrm{g} / \mathrm{gSS})$ in the cake layer was only a little higher than that in the sludge $(111.0 \mu \mathrm{g} / \mathrm{gSS})$ in the CUF system. However, in the parallel CAUF system, the amounts were $151.5 \mu \mathrm{g} / \mathrm{gSS}$ and $53.0 \mu \mathrm{g} / \mathrm{gSS}$, respectively. The ratio of polysaccharide between the cake layer and sludge in the CUF was much lower than that in the CAUF, indicating that the concentration of polysaccharides in the CAUF cake layer increased greatly after a long operation time. The variation of protein extracted from the cake layer and sludge in the two membrane systems was very similar to that of polysaccharide. Comparing the results given in Fig. 5a and b with Fig. 2, it is suggested that the large increase in TMP after 20 days of operation in the first stage was caused by a dramatic increase in the EPS concentration during that period.

In comparison with the EPS results, the variation of DNA concentration in the two membrane systems further confirmed these results. The DNA extracted from the cake layer in the CUF $(9.6 \mu \mathrm{g} / \mathrm{gSS})$ was very similar to that from the sludge $(10.7 \mu \mathrm{g} / \mathrm{gSS})$, whereas the DNA in the CAUF cake layer $(10.3 \mu \mathrm{g} / \mathrm{gSS})$ was much higher than that in the sludge $(4.9 \mu \mathrm{g} / \mathrm{gSS})$. The ratio of DNA values between the cake layer and sludge in the CAUF (2.1) was much greater than that in the CUF (0.9). The results indicate that the greater accumulated biodegradable DOM concentration in the CAUF cake layer provided nutrition for the microorganisms and increased their concentration. The increase of microorganisms after approximately 28 days of operation in the first stage showed that some metabolites were secreted to extracellular space and became the composition of bound EPS. According to the research by Cai and Benjamin [57], polysaccharides sometimes play a key role in membrane fouling. Therefore, a greater amount of bound EPS per unit SS was reasonably expected in the cake layer of CAUF. As a conclusion, the results suggest that the coagulation-PAC cake layer should be washed away after a long operation time.

\subsection{SEM images}

Figs. 6 and 7 present images of clean and fouled UF membranes, and their cross-sectional images. For the clean membrane there were a great number of large pores within the membrane 
a
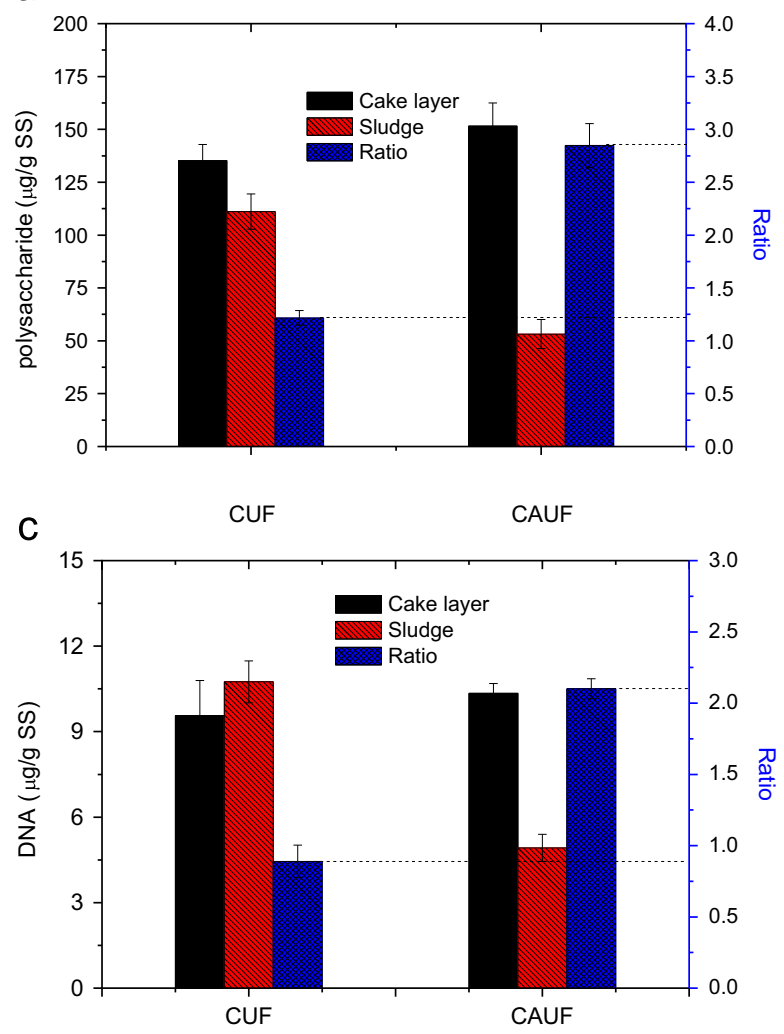

b

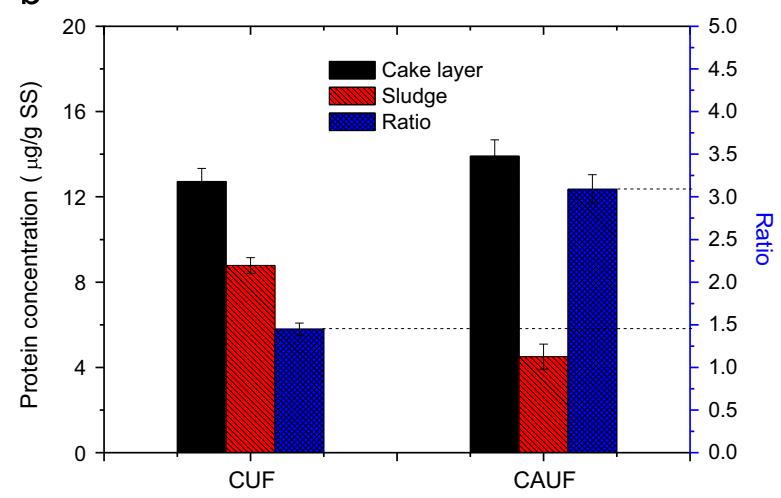

Fig. 5. The concentrations of polysaccharide (a), protein (b) and DNA (c) in the UF cake layers and sludges.

surface and the pore distribution appeared relatively uniform (Fig. 6a). In contrast, used membranes displayed a thick deposit layer over the surface of the membranes; however, the differences in the appearance of the cake layers deposited on the membrane surface by the two different pretreatments were not apparent (Fig. 6b and c). The cake layers of both looked like colloidal deposits and appeared relatively porous, and the PAC in the CAUF appeared to be hidden in the cake layer. From their appearance it is speculated that both cake layers were formed from the accumulation of nano-scale primary particles of around $30 \mathrm{~nm}$.

After removal of the cake layer by washing to explore the evidence of internal membrane fouling, the number of pores on the two fouled membrane surfaces was noticeably different (Fig. 6d and e). It could be seen that the number of pores, and particularly large pores, on the membrane surface of CUF was much less than on the membrane surface of CAUF. The results of microscopic observations demonstrated that the internal fouling induced by the deposition or blockage of the membrane pores of the CUF was much more serious than that of CAUF, which was consistent with the results of internal fouling resistances described by the TMP of both systems (after high-pressure water wash and sponge) (Fig. 2).

Comparing the thickness of the cake layer formed by the two pretreatments, it is evident that the addition of $10 \mathrm{mg} / \mathrm{L} \mathrm{PAC}$ increased the thickness of the cake layer in the CAUF system (Fig. 7a and c). This can be partly explained by the effect of the greater presence of polysaccharide (Fig. 5a) in the CAUF system, which might have increased the bonding capacity of the cake layer.

Also, it is visible in Fig. 7a and $b$ that for the CUF membrane the primary particles in the inner cake layer $(<7 \mu \mathrm{m})$ seem to be smaller than those in the outer cake layer. A possible reason for this is that these nano-scale primary particles may desorb organic matter from their surface because of the crystallization process (see Section 3.6), and form smaller primary particles, thereby causing a higher density of cake layer. The desorbed DOM from the cake layer and residual DOM after coagulation subsequently passed to the surface of the CUF membrane, causing higher irreversible membrane fouling compared to the CAUF system. In contrast, the presence of PAC particles in the CAUF cake layer seems to prevent the desorbing of DOM and the passage of organic material to the surface of the CAUF membrane, thereby causing lower internal membrane fouling, which is indicated by the information presented in Figs. 3 and 6.

\subsection{Crystallization of cake layer}

The structure and properties of flocs and cake layers may change with time via an aging process involving crystallization, which may induce higher membrane fouling; however, little has been published on this phenomenon. Therefore, the crystallization of cake layers was explored in this study by XRD, as well as new sludge for comparison.

The results shown in Fig. 8 indicate that there was no crystallization of the newly formed sludge, confirming that the sludge is formed by amorphous flocs. In contrast, it is clear that there were crystalline phases in both CUF and CAUF cake layers, demonstrating that the coagulant sludge undergoes an aging process involving crystallization. The results did not show any significant difference in the crystalline nature of the CUF and CAUF cakes, suggesting that the presence of PAC did not affect the crystalline process during the period of membrane operation.

It is possible that the cake crystallization process is responsible for the desorption of DOM from the surface of nano-scale primary particles, which comprise the cake layer, as referred to earlier. 

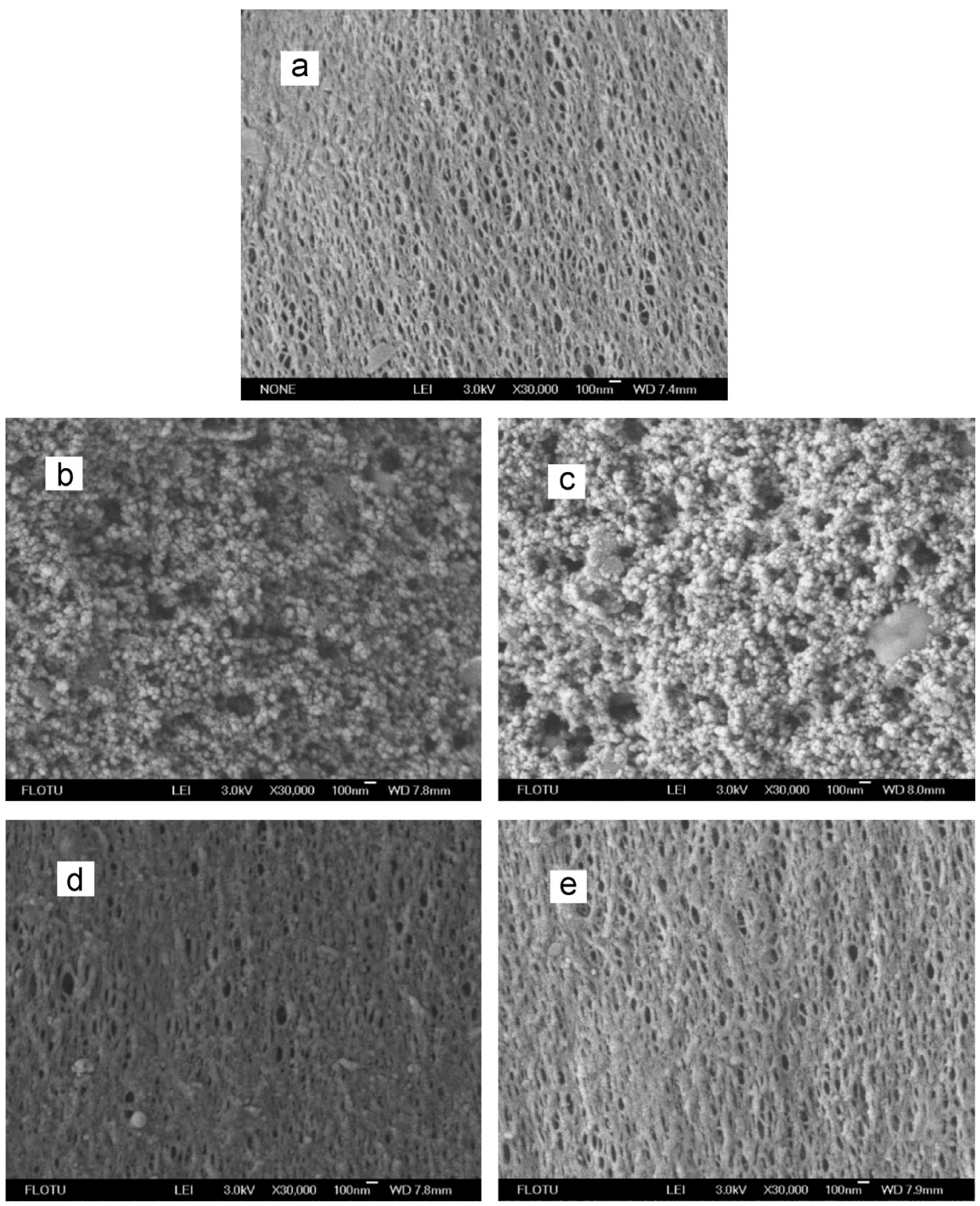

Fig. 6. Images of membranes with different pretreatments ( $\times$ 30,000 fold): (a) new membrane, (b) CUF with cake layer, (c) CAUF with cake layer, (d) CUF after sponge wash, (e) CAUF after sponge wash.

\section{Discussion}

According to our previous experiments, a large proportion of DOM is removed (precipitated/enmeshed by alum hydrolysis) after 1 min rapid mixing in the coagulation process, and part of the residual DOM is continuously retained/adsorbed by, and accumulated in, the developing cake layer of the UF membrane. Comparing the two UF systems, more residual NOM is adsorbed in the CAUF cake layer because of the presence of PAC (added to the first flocculation tank), and it is likely that a significant PAC adsorption capacity remains during the membrane filtration process. The accumulation of more DOM in the CAUF cake layer leads to a higher concentration of microorganisms in the CAUF cake layer, and consequently a greater quantity of EPS after a long operation time. According to Table $1, \mathrm{NH}_{4}^{+}-\mathrm{N}$ was removed less in the CAUF tank than in the CUF tank in the early period of the three operation stages, which meant that there was a lower concentration of microorganisms in the CAUF membrane tank. However, $\mathrm{NH}_{4}^{+}-\mathrm{N}$ was removed to a greater extent by the CAUF cake layer after a long operation time (as indicated in Stage 1), and this could be attributed to the development of a higher concentration of microorganisms with increasing run time.

Tsuneda et al. [58] reported that sludge adhesion was enhanced by polymeric interactions when the bound EPS content increased. Sludge with abundant bound EPS tends to adhere to the membrane surface and form a stable structure, which could prevent the cake layer from being washed away. The bound EPS has a considerable effect on the initial adhesion of sludge flocs to the membrane surface and the cake layer development, especially for polysaccharides. It has been proposed that polysaccharides can mediate the attachment between bacterial cells by intermolecular cross-linkages via polyvalent cations, which is critical for cake layer formation. The higher concentration of EPS determined in the CAUF cake layer (Fig. 5a and b) is consistent with the results observed. The addition of PAC accumulated organic matter and induced a higher concentration of microorganisms, which produced a higher concentration of bound EPS after a long operation time, forming a thicker cake layer (Fig. 7). The presence of a substantial concentration of soluble organics, especially polysaccharide, in the synthetic raw water may also have contributed to 

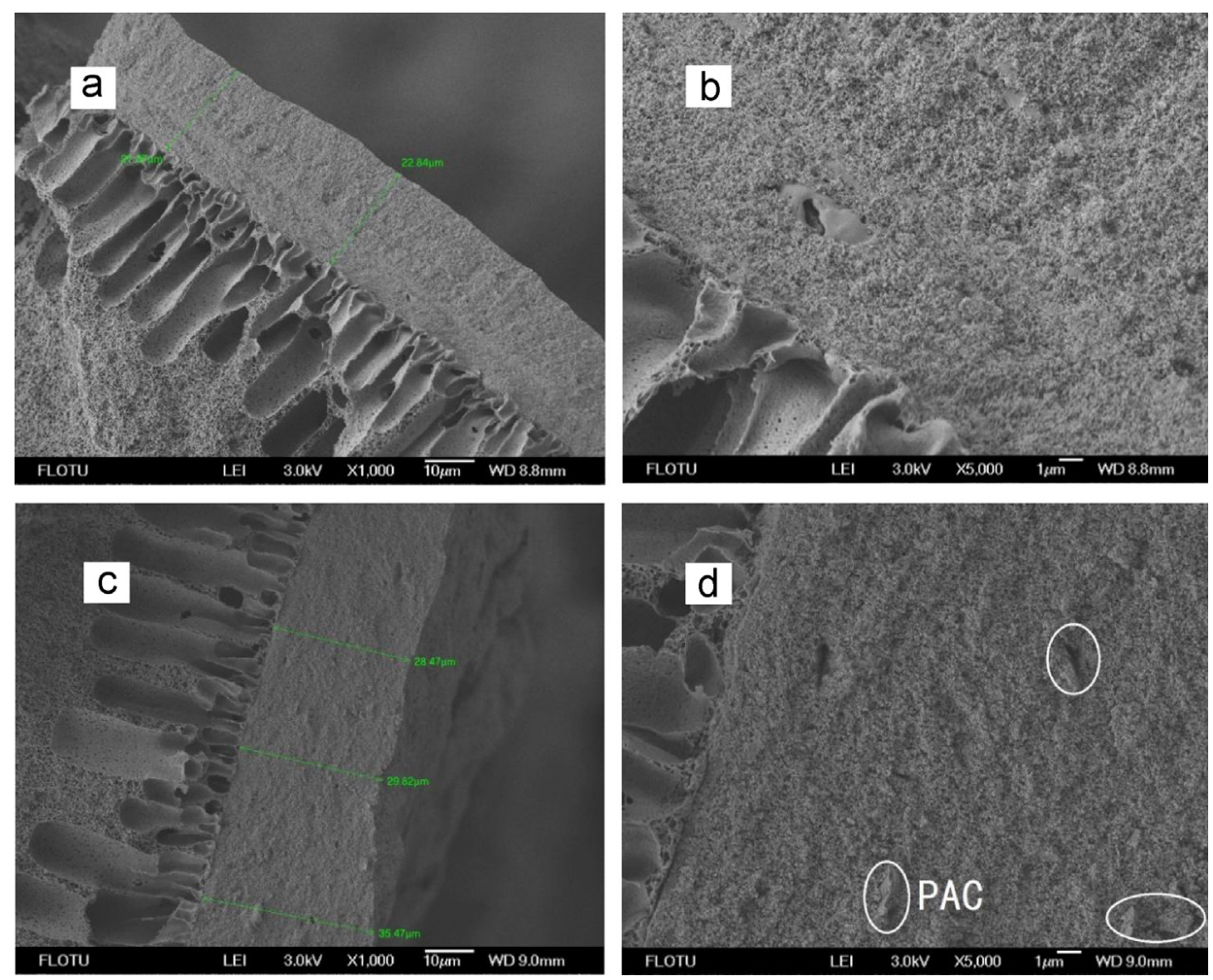

Fig. 7. Images of membranes with different pretreatments in cross-section: (a) $\times 1000$ CUF, (b) $\times 5000$ CUF, (c) $\times 1000$ CAUF, (d) $\times 5000$ CAUF.

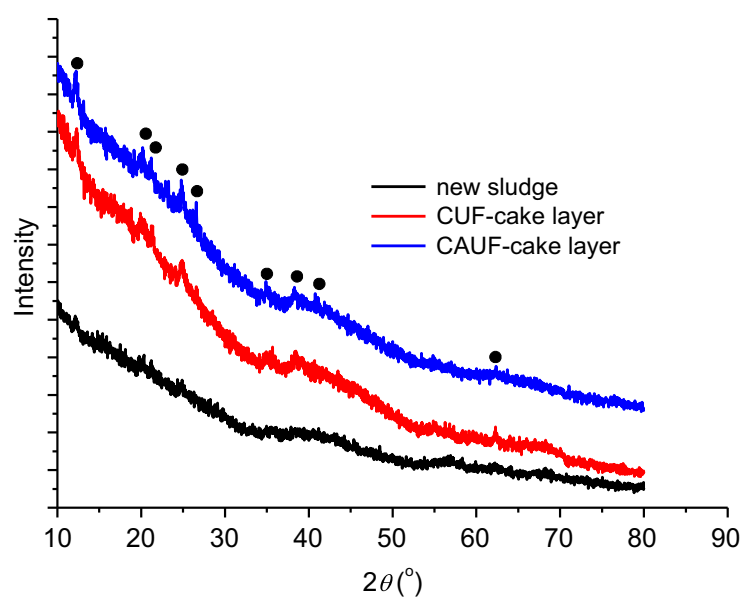

Fig. 8. XRD patterns of new sludge and the cake layers of the CUF and CAUF membranes at the end of the first stage of operation (there were no peaks for CUF and CAUF new sludges).

the accumulation of polysaccharide in the CAUF cake layer, because of the presence of PAC. In most cases, deposition of foulant material is found both on the external membrane surface and inside microfiltration (MF) and ultrafiltration (UF) membrane pores [51]. Comparing the EPS concentration extracted from the two membrane fibers, the concentration from the CAUF was much lower than from the CUF, which suggested that some additional EPS or DOM was adsorbed by the PAC in the CAUF system and was retained within the cake layer, thereby reducing the EPS arriving at the membrane surface.

According to the SEM images (Fig. 7), the size of primary coagulation particles appeared to decrease after a long operation time ( $>20$ days) and this was associated with an increase in crystallization (Fig. 8). One of the consequences of this is that the density of the cake layer increased with time, and it is also believed that organic matter previously adsorbed on the nanoscale primary particles subsequently desorbed. Thus, in the CUF system, DOM desorbed from the cake layer and passed through the cake layer to the membrane surface, where it contributed to blocking of the membrane pores (increased the internal membrane fouling). In contrast, in the CAUF system, the addition of PAC produced a higher porosity of the cake layer, and re-adsorbed the desorbed DOM, thereby preventing it from reaching the surface of the cake layer, which in turn caused a lower increase of reversible and irreversible membrane fouling; a schematic of the mechanisms is given in Fig. 9. The impact of this is a reduced rate of increase in TMP, as demonstrated in the results shown in Fig. 2. However, with increasing operation time (more than 20 days), the contribution of an increasing concentration of microorganisms within the cake layer, with their associated EPS, negated the beneficial effects of PAC and caused a greater rate of TMP increase. Thus, the operation run time of the CAUF system needs to be optimized in order to minimize the deleterious effects of microorganism growth.

\section{Conclusions}

(1) The addition of a low dosage of PAC with alum coagulation can effectively mitigate both irreversible and reversible UF membrane fouling, for membrane run periods of less than 20 days.

(2) The addition of PAC during alum coagulation produced a greater removal of DOM, and particularly proteinaceous material, from the treated water, compared to alum coagulation without PAC.

(3) During UF filtration, crystallization of the coagulation flocs decreased the size of the primary particles and decreased the porosity of the cake layer; the presence of PAC did not affect the crystallization process.

(4) It is speculated that bound DOM desorbed from the surface of particles during crystallization which, together with residual 


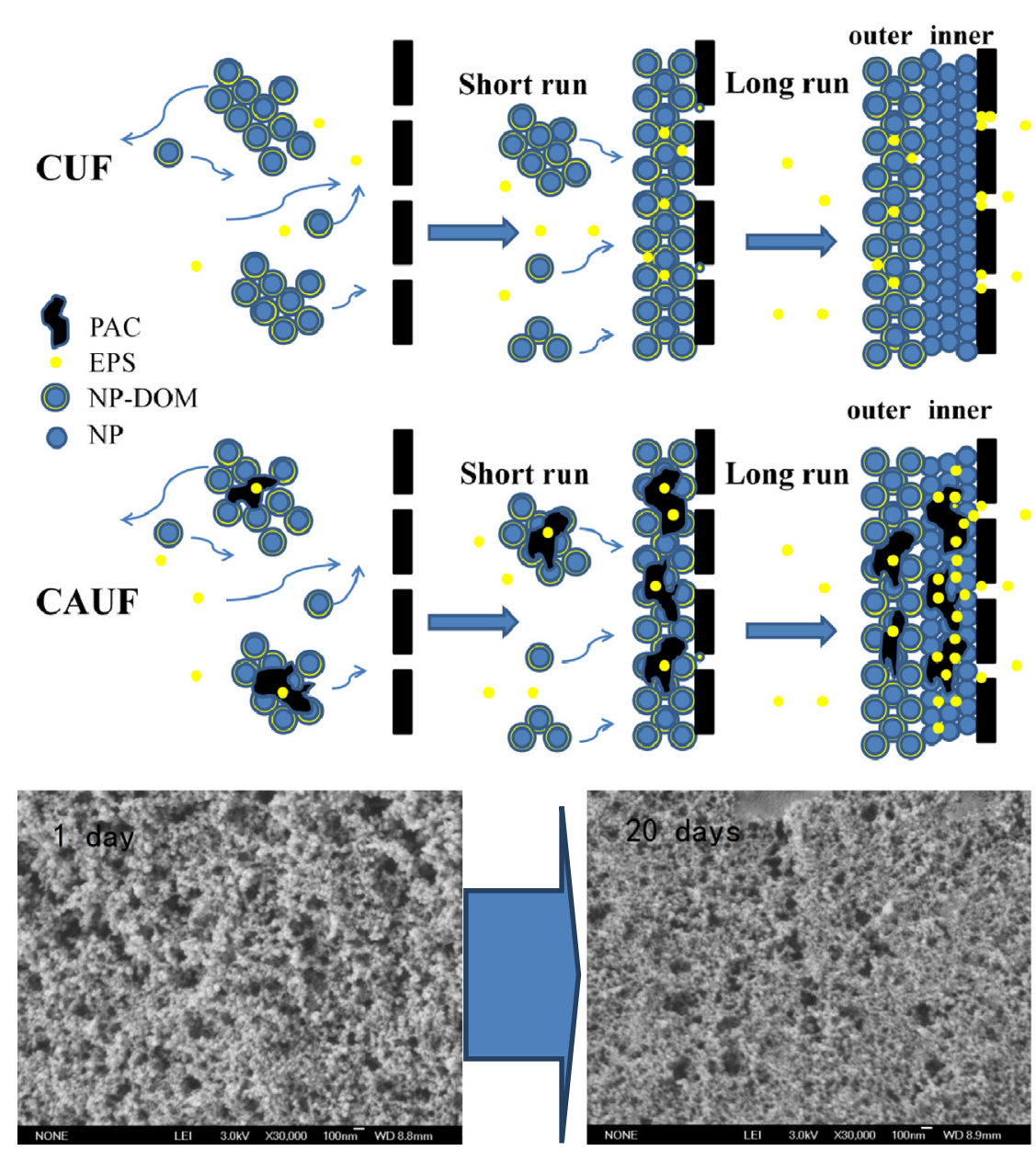

Fig. 9. Schematic of fouling mechanisms for the CUF and CAUF systems (NP: nano-scale primary particles).

DOM after coagulation, passed through the cake layer, thereby blocking the pores and increasing the extent of irreversible membrane fouling (in the CUF system).

(5) The presence of PAC in the CAUF system was able to re-adsorb DOM desorbed from the cake layer and residual DOM after coagulation, and thereby prevent DOM from reaching the membrane surface and contributing to internal membrane fouling.

(6) For membrane run periods greater than 20 days the substantial development of microorganisms and associated EPS, assisted by the presence of $\mathrm{PAC}$, produced a greater degree of membrane fouling, and increased the rate of TMP development.

\section{Acknowledgments}

This work was supported by the National Natural Science Foundation of China (Grants 51138008 and 51108444) and partly by the National Science \& Technology Project in Countryside (2012BAJ25B00). The work was also supported by EU Marie Curie International Incoming Fellowships (FP7-PEOPLE-2012-IIF-328867).

\section{Appendix A. Supporting information}

Supplementary data associated with this article can be found in the online version at http://dx.doi.org/10.1016/j.memsci.2014.02.005.

\section{References}

[1] W. Yuan, A.L. Zydney, Humic acid fouling during ultrafiltration, Environ. Sci. Technol. 34 (23) (2000) 5043-5050.

[2] N. Her, G. Amy, D. McKnight, J. Sohn, Y. Yoon, Characterization of DOM as a function of MW by fluorescence EEM and HPLC-SEC using UVA, DOC, and fluorescence detection, Water Res. 37 (17) (2003) 4295-4303.

[3] C.F. Lin, T.Y. Lin, O.J. Hao, Effects of humic substance characteristics on UF performance, Water Res. 34 (2000) 1097-1106.

[4] C.N. Laabs, G.L. Amy, M. Jekel, Understanding the size and character of foulingcausing substances from effluent organic matter (EfOM) in low-pressure membrane filtration, Environ. Sci. Technol. 40 (2006) 4495-4499.

[5] H. Huang, N. Lee, T. Young, G. Amy, J.C. Lozier, J.G. Jacangelo, Natural organic matter fouling of low-pressure, hollow-fiber membranes: effects of NOM source and hydrodynamic conditions, Water Res. 41 (2007) 3823-3832.

[6] K.Y.J. Choi, B.A. Dempsey, In-line coagulation with low-pressure membrane filtration, Water Res. 38 (19) (2004) 4271-4281.

[7] K. Konieczny, D. Sąkol, J. Płonka, M. Rajca, M. Bodzek, Coagulation-ultrafiltration system for river water treatment, Desalination 240 (1-3) (2009) 151-159.

[8] K. Listiarini, D.D. Sun, J.O. Leckie, Organic fouling of nanofiltration membranes: evaluating the effects of humic acid, calcium, alum coagulant and their combinations on the specific cake resistance, J. Membr. Sci. 332 (1-2) (2009) 56-62.

[9] P.K. Park, C.H. Lee, S.H. Lee, Permeability of collapsed cakes formed by deposition of fractal aggregates upon membrane filtration, Environ. Sci. Technol. 40 (2006) 2699-2705.

[10] J. Moon, M.S. Kang, J.L. Lim, C.H. Kim, H.D. Park, Evaluation of a low-pressure membrane filtration for drinking water treatment: pretreatment by coagulation/sedimentation for the MF membrane, Desalination 247 (2009) 271-284.

[11] S. Mozia, M. Tomaszewska, Treatment of surface water using hybrid processes adsorption on PAC and ultrafiltration, Desalination 162 (1-3) (2004) 23-31.

[12] U. Goren, A. Aharoni, M. Kummel, R. Messalem, I. Mukmenev, A. Brenner, V. Gitis, Role of membrane pore size in tertiary flocculation/adsorption/ ultrafiltration treatment of municipal wastewater, Sep. Purif. Technol. 61 (2) (2008) 193-203.

[13] M.M.T. Khan, S. Takizawa, Z. Lewandowski, M.H. Rahman, K. Komatsu, S.E Nelson, F. Kurisu, A.K. Camper, H. Katayama, S. Ohgaki, Combined effects of EPS 
and HRT enhanced biofouling on a submerged and hybrid PAC-MF membrane bioreactor, Water Res. 47 (2) (2013) 747-757.

[14] I. Ivancev-Tumbas, R. Hobby, B. Kuchle, S. Panglisch, R. Gimbel, p-Nitrophenol removal by combination of powdered activated carbon adsorption and ultrafiltration - comparison of different operational modes, Water Res. 42 (15) (2008) 4117-4124.

[15] J. Lee, H.W. Walker, Effect of process variables and natural organic matter on removal of microcystin-LR by PAC-UF., Environ. Sci. Technol. 40 (23) (2006) $7336-7342$.

[16] H.J. Hong, H. Kim, Y.J. Lee, J.W. Yang, Removal of anionic contaminants by surfactant modified powdered activated carbon (SM-PAC) combined with ultrafiltration, J. Hazard. Mater. 170 (2-3) (2009) 1242-1246.

[17] M.B. Dixon, Y. Richard, L. Ho, C.W.K. Chow, B.K. O'Neill, G. Newcombe, A coagulation-powdered activated carbon-ultrafiltration - multiple barrier approach for removing toxins from two Australian cyanobacterial blooms, J. Hazard. Mater. 186 (2-3) (2011) 1553-1559.

[18] J. Lohwacharin, K. Oguma, S. Takizawa, Use of carbon black nanoparticles to mitigate membrane fouling in ultrafiltration of river water, Sep. Purif. Technol. 72 (1) (2010) 61-69.

[19] M. Tomaszewska, S. Mozia, Removal of organic matter from water by PAC/UF system, Water Res. 36 (16) (2002) 4137-4143.

[20] M. Campinas, M.J. Rosa, Assessing PAC contribution to the NOM fouling control in PAC/UF systems, Water Res. 44 (5) (2010) 1636-1644.

[21] J.Y. Tian, H. Liang, Y.L. Yang, S. Tian, G.B. Li, Membrane adsorption bioreactor (MABR) for treating slightly polluted surface water supplies: as compared to membrane bioreactor (MBR), J. Membr. Sci. 325 (1) (2008) 262-270.

[22] Y. Satyawali, M. Balakrishnan, Effect of PAC addition on sludge properties in an MBR treating high strength wastewater, Water Res. 43 (6) (2009) 1577-1588.

[23] J.L. Acero, F.J. Benitez, F.J. Real, F. Teva, Coupling of adsorption, coagulation, and ultrafiltration processes for the removal of emerging contaminants in a secondary effluent, Chem. Eng. J. 210 (2012) 1-8.

[24] C.A. Ng, D. Sun, J.S. Zhang, B. Wu, A.G. Fane, Mechanisms of fouling control in membrane bioreactors by the addition of powdered activated carbon, Sep. Sci. Technol. 45 (7) (2010) 873-889.

[25] C.F. Lin, Y.J. Huang, I.J. Hao, Ultrafiltration processes for removing humic substances: effect of molecular weight fractions and PAC treatment, Water Res. 33 (5) (1999) 1252-1264.

[26] L.C. Schideman, B.J. Marinas, V.L. Snoeyink, S.Y. Qi, C. Campos, Three-component adsorption modeling to evaluate and improve integrated sorption-membrane processes, Environ. Sci. Technol. 41 (18) (2007) 6547-6553.

[27] S. Leveille, A. Carriere, S. Charest, B. Barbeau, PAC membrane bioreactor as an alternative to biological activated carbon filters for drinking water treatment, J. Water Supply Res. Technol.-Aqua 62 (1) (2013) 23-34.

[28] J.S. Kim, Z.X. Cai, M.M. Benjamin, Effects of adsorbents on membrane fouling by natural organic matter, J. Membr. Sci. 310 (1-2) (2008) 356-364.

[29] S.K. Kang, K.H. Choo, Why does a mineral oxide adsorbent control fouling better than powdered activated carbon in hybrid ultrafiltration water treatment? J. Membr. Sci. 355 (1-2) (2010) 69-77.

[30] M.M. Zhang, C. Li, M.M. Benjamin, Y.J. Chang, Fouling and natural organic matter removal in adsorben/membrane systems for drinking water treatment, Environ. Sci. Technol. 37 (8) (2003) 1663-1669.

[31] Y.H. Li, X.J. Zhang, W. Zhang, J. Wang, C. Chen, Effect of powdered activated carbon on immersed hollow fiber ultrafiltration membrane fouling caused by particles and natural organic matter, Desalination 278 (1-3) (2011) 443-446.

[32] J.W. Lee, J.I. Chun, H.J. Jung, D.H. Kwak, T. Ramesh, W.G. Shim, H. Moon, Comparative studies on coagulation and adsorption as a pretreatment method for the performance improvement of submerged MF membrane for secondary domestic wastewater treatment, Sep. Sci. Technol. 40 (13) (2005) 2613-2632.

[33] J.W. Lee, S.P. Choi, R. Thiruvenkatachari, W.G. Shim, H. Moon, Submerged microfiltration membrane coupled with alum coagulation/powdered activated carbon adsorption for complete decolorization of reactive dyes, Water Res. 40 (3) (2006) 435-444.

[34] Y. Matsui, H. Hasegawa, K. Ohno, T. Matsushita, S. Mima, Y. Kawase, T. Aizawa, Effects of super-powdered activated carbon pretreatment on coagulation and trans-membrane pressure buildup during microfiltration, Water Res. 43 (20) (2009) 5160-5170.

[35] E. Dialynas, E. Diamadopoulos, Integration of immersed membrane ultrafiltration with coagulation and activated carbon adsorption for advanced treatment of municipal wastewater, Desalination 230 (1-3) (2008) 113-127.

[36] W.Z. Yu, J. Gregory, Y.L. Yang, M. Sun, T. Liu, G.B. Li, The effect of coagulation and applied breakage shear on the re-growth of kaolin flocs, Environ. Eng. Sci. 27 (6) (2010) 483-492.
[37] W.Z. Yu, H.J. Liu, L. Xu, J.H. Qu, N. Graham, The pre-treatment of submerged ultrafiltration membrane by coagulation - Effect of polyacrylamide as a coagulant aid, J. Membr. Sci. 446 (2013) 50-58.

[38] Z.W. Wang, Z.C. Wu, S.J. Tang, Characterization of dissolved organic matter in a submerged membrane bioreactorby using three-dimensional excitation and emission matrix fluorescence spectroscopy, Water Res. 43 (6) (2009) $1533-1540$.

[39] Z.Y. Yu, X.H. Wen, M.L. Xu, X. Huang, Characteristics of extracellular polymeric substances and bacterial communities in an anaerobic membrane bioreactor coupled with online ultrasound equipment, Bioresour. Technol. 117 (2012) $333-340$.

[40] K. Kimura, T. Naruse, Y. Watanabe, Changes in characteristics of soluble microbial products in membrane bioreactors associated with different solid retention times: relation to membrane fouling, Water Res. 43 (4) (2009) 1033-1039.

[41] M. Dubois, K.A. Gilles, J.K. Hamilton, P.A. Rebers, F. Smith, Colorimetric method for determination of sugars and related substances, Anal. Chem. 28 (3) (1956) $350-356$.

[42] G. Peterson, A simplification of the protein assay method of Lowry et al. which is more generally applicable, Anal. Biochem. 83 (2) (1977) 346-356.

[43] T. Zhang, H.H.P. Fang, Digitization of DGGE (denaturing gradient gel electrophoresis) profile and cluster analysis of microbial communities, Biotechnol. Lett. 22 (2000) 399-405.

[44] B.P. Allpike, A. Heitz, C.A. Joll, R.I. Kagi, G. Abbt-Braun, F.H. Frimmel, T. Brinkmann, N. Her, G. Amy, Size exclusion chromatography to characterize doc removal in drinking water treatment, Environ. Sci. Technol. 39 (2005) 2334-2342.

[45] APHA, 2005. Standard Methods for the Examination of Water and Wastewater (twenty-first ed.), American Public Health Association/American Water Works Association/Water Environmental Federation, Washington DC, USA

[46] A. Baker, Fluorescence excitation-emission matrix characterization of some sewage-impacted rivers, Environ. Sci. Technol. 35 (5) (2001) 948-953.

[47] A. Baker, R. Inverarity, M. Charlton, S. Richmond, Detecting river pollution using fluorescence spectrophotometry: case studies from the Ouseburn, NE England, Environ. Pollut. 124 (1) (2003) 57-70.

[48] J. Chen, B. Gu, E.J. LeBoeuf, H. Pan, S. Dai, Spectroscopic characterization of the structural and functional properties of natural organic matter fractions, Chemosphere 48 (2002) 59-68.

[49] J. Swietlik, A. Dabrowska, U. Raczyk-Stanis1awiak, J. Nawrocki, Reactivity of natural organic matter fractions with chlorine dioxide and ozone, Water Res. 38 (3) (2004) 547-558.

[50] R.H. Peiris, H. Budman, C. Moresoli, R.L. Legge, Understanding fouling behaviour of ultrafiltration membrane processes and natural water using principal component analysis of fluorescence excitation-emission matrices, J. Membr. Sci. 357 (1-2) (2010) 62-72.

[51] I.S. Chang, P. Le Clech, B. Jefferson, S. Judd, Membrane fouling in membrane bioreactors for wastewater treatment, J. Environ. Eng.-ASCE 128 (2002) 1018-1029.

[52] S.H. Hong, W.N. Lee, H.S. Oh, K.M. Yeon, B.K. Hwang, C.H. Lee, I.S. Chang, S. Lee The effects of intermittent aeration on the characteristics of bio-cake layers in a membrane bioreactor, Environ. Sci. Technol. 41 (17) (2007) 6270-6276.

[53] A. Drews, J. Mante, V. Iversen, M. Vocks, B. Lesjean, M. Kraume, Impact of ambient conditions on SMP elimination and rejection in MBRs, Water Res. 41 (17) (2007) 3850-3858.

[54] D. Al-Halbouni, J. Traber, S. Lyko, T. Wintgens, T. Melin, D. Tacke, A. Janot, W. Dott, J. Hollender, Correlation of EPS content in activated sludge at different sludge retention times with membrane fouling phenomena, Water Res. 42 (6-7) (2008) 1475-1488.

[55] D. Al-Halbouni, W. Dott, J. Hollender, Occurrence and composition of extracellular lipids and polysaccharides in a full-scale membrane bioreactor, Water Res. 43 (1) (2009) 97-106.

[56] H.J. Lin, B.Q. Liao, J.R. Chen, W.J. Gao, L.M. Wang, F.Y. Wang, X.F. Lu, New insights into membrane fouling in a submerged anaerobic membrane bioreactor based on characterization of cake sludge and bulk sludge, Bioresour. Technol. 102 (3) (2011) 2373-2379.

[57] Z.X. Cai, M.M. Benjamin, NOM fractionation and fouling of low-pressure membranes in microgranular adsorptive filtration, Environ. Sci. Technol. 45 (20) (2011) 8935-8940.

[58] S. Tsuneda, H. Aikawa, H. Hayashi, A. Yuasa, A. Hirata, Extracellular polymeric substances responsible for bacterial adhesion onto solid surface, FEMS Microbiol. Lett. 223 (2003) 287-292. 